\title{
Evaluation of Peripheral Neuropathy in Diabetic Adults with and without Foot Ulcers in an African Population
}

\author{
Osita Ede $\complement^{\circledR}$, Gabriel O. Eyichukwu, Kenechi A. Madu, Iheuko S. Ogbonnaya, \\ Kelechukwu A. Okoro, Chinonso Basil-Nwachuku, Kelechi A. Nwokocha \\ Department of Orthopaedics, Plastic and Reconstructive Surgery, National Orthopaedic Hospital, Enugu, Nigeria \\ Email: edeosita@yahoo.com,drgoeyichs@yahoo.com, kenemadu@yahoo.com, iheukoogbonnaya@gmail.com, \\ okoroka@gmail.com, krystarays@yahoo.co.uk, Nwokocha.kelechi@yahoo.com
}

How to cite this paper: Ede, O., Eyichukwu, G.O., Madu, K.A., Ogbonnaya, I.S.., Okoro, K.A., Basil-Nwachuku, C. and Nwokocha, K.A. (2018) Evaluation of Peripheral Neuropathy in Diabetic Adults with and without Foot Ulcers in an African Population. Journal of Biosciences and Medicines, 6, 71-78.

https://doi.org/10.4236/jbm.2018.612007

Received: November 7, 2018

Accepted: December 11, 2018

Published: December 14, 2018

Copyright $\odot 2018$ by authors and Scientific Research Publishing Inc. This work is licensed under the Creative Commons Attribution International License (CC BY 4.0).

http://creativecommons.org/licenses/by/4.0/

\begin{abstract}
Background: Foot ulcers frequently precede lower extremity amputations (LEA) in diabetic subjects. Peripheral neuropathy (PN) is a strong risk factor for diabetic foot ulceration. Majority of diabetic patients with PN are asymptomatic; hence foot ulceration may be the first clinical presentation. Early detection of PN can forestall the development of foot ulcers through active preventive strategies. Few studies have been done to assess PN in diabetic individuals in Africa. The study aims to evaluate the incidence and risk factors for $\mathrm{PN}$ in diabetic adults with and without foot ulcers in an indigenous African population. Method: This cross-sectional study involved 90 diabetic adults, 45 with foot ulcers and 45 without foot ulcers. Assessment of PN was done with the Michigan Neuropathy Screening Instrument (MNSI), the $10 \mathrm{~g}$ Semmes-Weinstein monofilament (SWM) and the $128-\mathrm{Hz}$ vibrating tuning fork (VTF). Demographic data were collected by questionnaire. Associations between PN and risk factors such as age, alcohol consumption, duration of diabetes, cigarette smoking, BMI, height and sex were also investigated. Results: There were 59 males (65.6\%) and 31 females (34.4\%) in the study. The mean age of the subjects with foot ulcers was 59.62 years $(\mathrm{SD}=6.47)$, while those without ulcers was 57.47 years $(\mathrm{SD}=6.94)$. Forty-two subjects $(93.33 \%)$ with foot ulcers have PN using the MNSI, while 33 subjects without foot ulcers (73.33\%) have PN. Both the SWM and the VTF showed a high positive correlation with themselves and with the MNSI. Advancing age, duration of diabetes, alcohol intake, hyperglycaemia and cigarette smoking showed a significant association with peripheral neuropathy, while BMI, height and sex did not. Conclusion: The incidence of PN is quite high in diabetic adults in Africa. This calls for early screening and aggressive control of risk factors to prevent the development of diabetic foot ulceration.
\end{abstract}




\section{Keywords}

Peripheral Neuropathy, African, Diabetic Adults, Foot Ulcers

\section{Introduction}

Diabetes mellitus (DM) is a growing worldwide pandemic [1]. Therefore, the incidence of complications of DM is expected to increase. Diabetic foot disease is one of the significant complications of DM. Ulceration, infection and gangrene continue to plague the diabetic population. It is estimated that a lower limb is lost every 30 seconds due to diabetes in some parts of the world [2]. In our centre, anecdotal evidence suggests that LEA for diabetic foot ulcers and gangrene accounts for about $80 \%$ of amputations done.

Peripheral neuropathy is an independent risk factor for diabetic foot ulceration [3] [4]. Sensory neuropathy leads to blunting of pain sensation; hence minor foot trauma may go unrecognised creating breaks in the skin integrity. Autonomic neuropathy leads to drying and fissuring of the skin due to the loss of the moisturising effects of sweats. Motor neuropathy leads to unbalanced muscle actions of the foot with altered foot biomechanics, which leads to deformities and uneven pressure distributions at the plantar aspect of the foot [1] [2] [5].

More than $85 \%$ of LEA in diabetic subjects results from the progression of a foot ulcer [2]. Amputation results in significant psychological, social and economic problems for the patient, due to the depression, the societal stigmatisation and the occasional job loss occasioned by the loss of a limb. The problem is worse in Africa where widespread poverty and inadequate health insurance would impede the acquisition of efficient prostheses that would offset some of these problems. Even when overt gangrene has not yet complicated a foot ulcer, treating an ulcer drains the financial resources of the patient. It was in 2006 estimated that the average cost of managing a diabetic foot ulcer in Nigeria is N180,582 (approximately €450), while the minimum monthly salary of a government worker is $\$ 18,000$ (about $€ 45$ ) in comparison [6]. The treatment cost is expected to have increased today due to inflation without a corresponding increase in the monthly salary.

It follows then that the identification of PN in the diabetic patient in Africa is imperative. Screening with simple validated tools such as the MNSI is one way of doing this [7]. Other less complicated quicker methods include the 5.07/10g SWM and the $128-\mathrm{Hz}$ VTF [8]. Combination of more than one test results in higher sensitivity than either test used alone [4]. The MNSI is a more comprehensive tool and combined both the SWM and the VTF, in addition to questions regarding the symptoms of sensory neuropathy.

Factors such as age, duration of diabetes, obesity, alcohol intake, cigarette smoking, poor glucose control have been variously cited as risk factors for the development of neuropathy [4]. Such factors have not been extensively studied 
in the African diabetic population. Therefore, the aim of this study is threefold: first, to identify the incidence of PN in diabetic adults with and without foot ulcers; second, to compare the sensitivities of the SWM and the VTF against the MNSI in the screening for peripheral neuropathy in diabetic adults; last, to identify risk factors for PN in African diabetic adults.

\section{Patients and Methods}

The study was a cross-sectional study done at the National Orthopaedic Hospital, Enugu (NOHE), from June 2016 to July 2017. National Orthopaedic Hospital, Enugu is a tertiary hospital, and the regional centre for Orthopaedics, Trauma, Plastic and Reconstructive Surgery in the South-Eastern part of the country. The test group was 45 diabetic adults with foot ulcers, while the control group was 45 diabetic adults without foot ulcers. Inclusion criteria were diabetic adults over the age of 50 years who have been diabetic for at least one year. Exclusion criteria were subjects with LEA, gangrene of the foot, temporal hyperglycaemic state such as gestational diabetes, clinically unstable patients such as ketoacidosis, other known causes of neuropathy such as rheumatoid arthritis, cognitive impairment and patients that refuse consent. Subjects were recruited from the clinics and the wards. Convenient sampling was used to gather as many participants as possible.

The formula for calculating the sample size for a comparison between two independent groups when the endpoint is qualitative is [9]:

$$
\frac{n=2[Z \alpha / 2+Z \beta]^{2} P(I-P)}{\left(P_{1}-P_{2}\right)^{2}}
$$

where

$\mathrm{n}=$ Number of participants in each group

$\mathrm{Z} \alpha / 2=1.96$ at $5 \% \alpha$-level of significance (from $\mathrm{Z}$ table)

$\mathrm{Z} \beta=0.842$ at $80 \%$ power (From $\mathrm{Z}$ table)

$(\mathrm{P} 1-\mathrm{P} 2)=$ Difference in proportion of events in the two groups

$$
P=\text { Pooled prevalence }=\frac{\text { Prevalence in group } 1+\text { prevalence in group } 2}{2}
$$

Ikem noted a prevalence of $49 \%$ of peripheral neuropathy in people with diabetes without foot ulcers using the Semmes-Weinstein monofilament [10], while another study gave a prevalence of $80 \%$ in people with diabetes with foot ulcers [11]. Combination of these figures gives a pooled prevalence of 0.645 , i.e. $\left\{\frac{0.49+0.80}{2}\right\}$.

Substituting into the equation

$$
n=\frac{2[1.96+0.842]^{2} \times 0.645(1-0.645)}{(0.8-0.49)^{2}}
$$

$$
n=37.4
$$


Peripheral neuropathy was assessed by the 5.07/10g SWM (marketed by Medline Company, Illinois USA). Nine sites on the plantar surface of the foot and one on the dorsum were tested. The sites are the pulp of the $1^{\text {st }}, 3^{\text {rd }}$ and $5^{\text {th }}$ toes, the metatarsal heads of the above toes, the medial and lateral aspects of the midfoot and the heel (see diagram). The dorsal surface of the first web space was tested. Failure to detect sensation in 3 or more places is considered positive for peripheral neuropathy [12].

Vibration perception was tested on the dorsum of the $1^{\text {st }}$ metatarsophalangeal joint with the $128 \mathrm{~Hz}$ VTF (marketed by BP Medical supplies, New York, USA). The fork was set into vibration and placed on the site on the big toe. When the subject stopped feeling the vibration, the fork was quickly transferred to the Examiner's radial styloid. If the examiner felt the sensation for longer than 5 seconds, it was considered to be reduced [7]. However, if the subject did not feel it at all, vibration perception was considered absent. Both reduced and absent sensation is regarded as abnormal and indicative of peripheral neuropathy.

The MNSI was also administered to each subject. It consists of a questionnaire part in which questions relating to the symptoms of PN are asked. Each item is scored, and the total score for that part is obtained. A score of 7 or above is abnormal. The examination part is done for each foot separately, and the scores for both feet are added together. A score of 2.5 or above is abnormal [7]. The blood glucose was checked with an electronic glucometer (Accu-chek Active), while the weight and the height were measured with an analogue scale (beurer $\mathrm{GmBH}$, Germany). The demographic data were collected with a structured questionnaire.

The data were analysed with the software IBM Statistical Package for Social Sciences (IBM SPSS) version 20. Chi-square test was used to assess the association between PN and gender, alcohol intake, and cigarette smoking. The Chi-square test was also used to test the difference in the sensitivities between the SWM and the 128-Hz VTF. The Pearson's correlation was assessed to assess the relationship between PN and age, duration of diabetes, quantity of alcohol consumed, and the fasting blood glucose concentration. A p-value of less than 0.05 was considered statistically significant.

\section{Results}

Subjects were relatively evenly matched with regards to gender in the two groups, see Figure 1. There was no statistically significant difference in the mean age of the two groups or the mean duration of diabetes between the two groups. The mean fasting blood glucose was higher in the ulcer group, and this difference was significant. Table 1 summarises the socio-demographic features and the clinical characteristics of the subjects.

Forty-two subjects (93.33\%) in the test group (those with foot ulcers) have PN as assessed by the MNSI, while this was present in 33 subjects $(73.33 \%)$ of the control (without foot ulcers). This difference is statistically significant ( $\mathrm{p}=$ 0.011 ). The sensitivity of the $128-\mathrm{Hz}$ VTF was $88.9 \%$ and $66.7 \%$ in the test and 
control groups respectively. The $10 \mathrm{~g}$ SWM has a slightly lower sensitivity of $84.4 \%$ and $62.2 \%$ in the test and control groups respectively. However, this difference was not significant $(\mathrm{p}=0.103)$. Both the VTF and the SWM showed a high inter-test positive correlation and also each correlated highly with the MNSI scores. Table 2 shows the paired samples correlation between the screening tests.

Age, duration of diabetes, alcohol intake, the quantity of alcohol consumed, smoking and hyperglycaemia were significantly associated with the occurrence of peripheral neuropathy. However, gender, BMI and height were not. Table 3 and Table 4 show the relationships between PN and the risk factors.

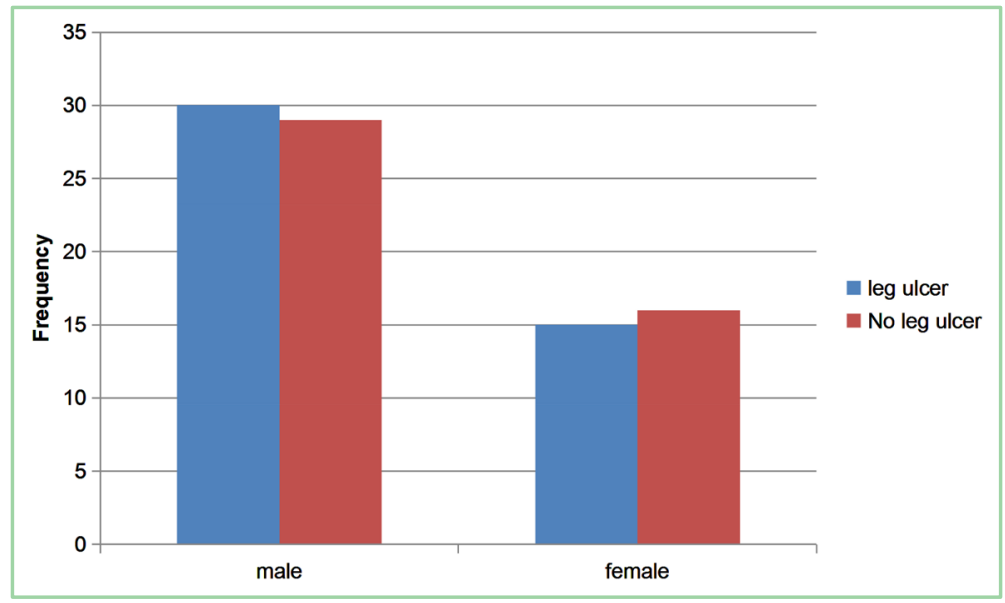

Figure 1. The sex distribution of the groups.

Table 1. The socio-demographic features and clinical characteristics of the participants (n $=90)$.

\begin{tabular}{cccc}
\hline Characteristics & Test group & Control group & p-value \\
\hline Gender & & & \\
Males & 30 & 29 & \\
Females & 15 & 16 & \\
Mean age $($ years $)$ & $59.62(\mathrm{SD}=6.47)$ & $57.47(\mathrm{SD}=6.94)$ & 0.131 \\
Mean duration of diabetes $($ years $)$ & $8.78(\mathrm{SD}=4.85)$ & $7.00(\mathrm{SD}=4.18)$ & 0.066 \\
Mean Fasting blood glucose $(\boldsymbol{m g} \mathbf{d})$ & $166.07(\mathrm{SD}=32.50)$ & $144.42(\mathrm{SD}=16.96)$ & $<0.001^{\star}$ \\
\hline
\end{tabular}

${ }^{*}=$ significant.

Table 2. Paired samples correlation between the screening tests for peripheral neuropathy.

\begin{tabular}{ccccc}
\hline & & $\boldsymbol{n}$ & correlation & Significance $(\boldsymbol{p})$ \\
\hline Pair 1 & SWM\&MNSI & 90 & 0.742 & $<0.001^{\star}$ \\
Pair 2 & VTF \& MNSI & 90 & 0.837 & $<0.001^{\star}$ \\
Pair 3 & VTF\&SWM & 90 & 0.826 & $<0.001^{\star}$ \\
\hline
\end{tabular}

MNSI $=$ Michigan Neuropathy Screening Instrument, VTF $=$ Vibrating Tuning Fork, $\mathrm{SWM}=$ Semmes Weinstein Monofilament. ${ }^{*}=$ significant. 
Table 3. Correlations between total MNSI scores and predictor variables (n).

\begin{tabular}{ccc}
\hline $\boldsymbol{n}$ & Correlation coefficient & $\boldsymbol{p}$-value \\
\hline Age & 0.322 & $0.002^{\star}$ \\
Duration of diabetes & 0.610 & $<0.001^{\star}$ \\
Grams of alcohol consumed per week & 0.703 & $<0.001^{\star}$ \\
Fasting blood glucose & 0.785 & $<0.001^{\star}$ \\
BMI & 0.028 & 0.790 \\
height & 0.070 & 0.514 \\
\hline
\end{tabular}

= significant associations.

Table 4. Associations between peripheral neuropathy and predictor variables (n).

\begin{tabular}{ccc}
\hline $\boldsymbol{n}$ & Chi-square test statistic $\left(\chi^{2}\right)$ & $\boldsymbol{p}$-value \\
\hline Cigarette smoking & 4.500 & 0.034 \\
Alcohol intake & 23.040 & $<0.001$ \\
SeX & 2.844 & 0.092 \\
\hline
\end{tabular}

= significant associations.

\section{Discussion}

This study has shown that the incidence of Peripheral neuropathy (PN) in the indigenous people of Africa with diabetes mellitus is quite high in both those with and those without foot ulcers. Ikem et al. got an incidence of $49 \%$ in diabetic subjects without foot ulcers [10], while Tabatabaei-Malazy et al. obtained a value of $80 \%$ in diabetic subjects with foot ulcers in Asia [11]. These differences might be attributable to two reasons. First, the two studies include patients younger than 50 years. It has been shown that advancing age is an independent risk factor for the development of peripheral neuropathy [4].

Second, the diagnosis was made with the $10 \mathrm{~g}$ SWM only. It has been shown that a combination of more than one test improves the sensitivity of the diagnosis [4]. However, the above values are closer to the values obtained with the monofilament in this study. Using monofilament, the incidence of neuropathy was $84 \%$ and $62 \%$ in subjects with and without foot ulcers respectively.

Our study did not demonstrate any superiority in sensitivity between the $10 \mathrm{~g}$ SWM and the $128 \mathrm{~Hz}$ VTF in screening for neuropathy. However, Kasznicki, in his systematic review implied that the tuning fork is more sensitive, especially in detecting subclinical sensory neuropathy [4]. Our findings agree with those of Olayele et al., who had shown that both the SWM and the VTF have comparable sensitivities and are easily reproducible [7].

Multivariate analyses showed that advancing age, duration of diabetes, smoking, alcohol intake and the quantity taken and poor glycaemic control are strongly related with the risk of developing peripheral neuropathy. A systematic review has found that the occurrence and the severity of $\mathrm{PN}$ are directly related to longer duration of diabetes and the severity of hyperglycaemia [4]. The effects 
of sustained hyperglycaemia on peripheral nerve have been extensively studied. Oxidative damage, advanced glycation end products, sorbitol production via the polyol pathway have all been implicated in nerve damage [4] [11] [13] [14].

Cigarette smoking was significantly associated with $\mathrm{PN}$ in our study. Other studies have found a similar association [2] [4]. Smoking causes neuropathy via ways including neuronal ischaemia from endothelial damage, oxidative stress, interference with glucose metabolism and from direct toxic effects on the neurons [15]. It has been difficult to quantify the amount of alcohol that is neurotoxic accurately. Factors such as individual variations in liver enzymes metabolic activity and concomitant vitamin deficiencies especially thiamine which is common in alcoholics can alter the clinical picture.

However, gender, height and BMI did not show any significant associations with the occurrence of PN in our study, which agrees with the findings by Katuland and colleagues who showed a weak correlation between PN, height and BMI [16]. In conclusion, much of the risk factors for PN among the African populace do not significantly differ from those elsewhere in the world.

\section{Conclusion and Recommendations}

The incidence of PN in diabetic subjects is quite high in Africa. Early screening with simple, inexpensive tools such as the $10 \mathrm{~g}$ SWM or the $128-\mathrm{Hz}$ VTF can lead to early detection and enable timely initiation of preventive measures to prevent the development of foot ulcers. Modifiable risk factors such as smoking, alcohol intake and poor glycaemic control should be actively moderated or stopped entirely in diabetic subjects.

\section{Ethical Considerations}

Ethical clearance was obtained from the Hospital's Ethical Committee for the study.

\section{Limitations}

A multicenter, multinational study could further highlight the similarities or differences in other African nations.

\section{Conflicts of Interest}

The authors declare no conflicts of interest regarding the publication of this paper.

\section{References}

[1] Frykberg, R.G., Armstrong, D.G., Giurini, J., et al. (2000) Diabetic Foot Disorders: A Clinical Practice Guideline. Vol. 45, No. 5. Data Trace Publishing Company.

[2] Papanas, N. and Maltezos, E. (2009) The Diabetic Foot: A Global Threat and a Huge Challenge for Greece. Hippokratia, 13, 199-204.

[3] Dros, J., Wewerinke, A., Bindels, P.J., et al. (2009) Accuracy of Monofilament Test- 
ing to Diagnose Peripheral Neuropathy: A Systematic Review. The Annals of Family Medicine, 7, 555-558. https://doi.org/10.1370/afm.1016

[4] Kasznicki, J. (2014) Advances in the Diagnosis and Management of Diabetic Distal Symmetric Polyneuropathy. Archives of Medical Science, 10, 345-354.

https://doi.org/10.5114/aoms.2014.42588

[5] Boulton, A.J.M., Vinik, A.I., Arezzo, J.C., et al. (2005) Diabetic Neuropathies A Statement by the American Diabetes Association. Diabetes Care, 28, 956-962. https://doi.org/10.2337/diacare.28.4.956

[6] Ogbera, A.O., Fasanmade, O., Ohwovoriole, A.E. and Adediran, O. (2006) An Assessment of the Disease Burden of Foot Ulcers in Patients with Diabetes Mellitus Attending a Teaching Hospital in Lagos, Nigeria. International Journal of Lower Extremity Wounds, 5, 244-249. https://doi.org/10.1177/1534734606294538

[7] Herman, W.H., Pop-Busui, R., Braffett, B.H., Martin, C.L., Cleary, P.A., Albers, J.W., et al. (2012) Use of the Michigan Neuropathy Screening Instrument as a Measure of Distal Symmetrical Peripheral Neuropathy in Type 1 Diabetes: Results from the Diabetes Control and Complications Trial/Epidemiology of Diabetes Interventions and Complications. Diabetic Medicine, 29, 937-944.

https://doi.org/10.1111/j.1464-5491.2012.03644.x

[8] Olaleye, D., Perkins, B.A. and Bril, V. (2001) Evaluation of Three Screening Tests and a Risk Assessment Model for Diagnosing Peripheral Neuropathy in the Diabetes Clinic. Diabetes Research and Clinical Practice, 54, 115-128. https://doi.org/10.1016/S0168-8227(01)00278-9

[9] Jaykaran, C. and Tamoghna, B. (2013) How to Calculate Sample Size for Different Study Designs in Medical Research_.html. Indian Journal of Psychological Medicine, 35, 121-126. https://doi.org/10.4103/0253-7176.116232

[10] Ikem, R.T. and Ikem, I.C. (2009) Screening and Identifying Diabetic Patients at Risk of Foot Ulceration: Use of Semmes-Weinstein Monofilament. Diabetes International, 17, 15-17.

[11] Tabatabaei-Malazy, O., Mohajeri-Tehrani, M., Madani, S., Heshmat, R., et al. (2011) The Prevalence of Diabetic Peripheral Neuropathy and Related Factors. Iranian Journal of Public Health, 40, 55-62.

[12] Nather, A., Keng Lin, W., Aziz, Z., et al. (2011) Assessment of Sensory Neuropathy in Patients with Diabetic Foot Problems. Diabetic Foot \& Ankle, 2. http://www.ncbi.nlm.nih.gov/pmc/articles/PMC3284271/

[13] Al-Nimer, M.S., Al-Ani, F.S. and Ali, F.S. (2012) Role of Nitrosative and Oxidative Stress in Neuropathy in Patients with Type 2 Diabetes Mellitus. Journal of Neurosciences in Rural Practice, 3, 41-44. https://doi.org/10.4103/0976-3147.91932

[14] Duran-Jimenez, B., Dobler, D., Moffatt, S., et al. (2009) Advanced Glycation end Products in Extracellular Matrix Proteins Contribute to the Failure of Sensory Nerve Regeneration in Diabetes. Diabetes, 58, 2893-2903.

https://doi.org/10.2337/db09-0320

[15] Clair, C., Cohen, M.J., Eichler, F., et al. (2015) The Effect of Cigarette Smoking on Diabetic Peripheral Neuropathy: A Systematic Review and Meta-Analysis. Journal of General Internal Medicine, 30, 1193-1203. https://doi.org/10.1007/s11606-015-3354-y

[16] Katulanda, P., Ranasinghe, P., Jayawardena, R., et al. (2012) The Prevalence, Patterns and Predictors of Diabetic Peripheral Neuropathy in a Developing Country. Diabetology \& Metabolic Syndrome, 4, 21. https://doi.org/10.1186/1758-5996-4-21 